\title{
PREDICTION OF DELAMINATION IN WIND TURBINE BLADE STRUCTURAL DETAILS
}

\author{
John F. Mandell, Douglas S. Cairns \\ Daniel D. Samborsky, Robert B. Morehead and Darrin J. Haugen \\ Montana State University \\ Bozeman, Montana 59717
}

\begin{abstract}
Delamination between plies is the root cause of many failures of composite materials structures such as wind turbine blades. Design methodologies to prevent such failures have not been widely available for the materials and processes used in blades. This paper presents simplified methodologies for the prediction of delamination under both static and fatigue loading at typical structural details in blades.

The methodology is based on fracture mechanics. The critical strain energy release rate, $\mathrm{G}_{\mathrm{IC}}$ and $\mathrm{G}_{\mathrm{IIC}}$, are determined for opening mode (I) and shearing mode (II) delamination cracks; fatigue crack growth in each mode is also characterized. These data can be used directly for matrix selection, and as properties for the prediction of delamination in structural details. The strain energy release rates are then determined for an assumed interlaminar flaw in the structural detail. The flaw is positioned based on finite element analysis (FEA), and the strain energy release rates are calculated using the virtual crack closure feature available in codes like ANSYS. The methodology has been validated for a skinstiffener intersection. Two prediction methods differing in complexity and data requirem ents have been explored. Results for both methods show good agreement between predicted and experimental delamination loads under both static and fatigue loading.
\end{abstract}

\section{INTRODUCTION}

Composite material structures such as wind turbine blades are generally designed to be fiber dominated, with 
the primary reinforcing fibers aligned with the primary load path to the extent possible. While significant challenges continue to exist in areas such as loads and lifetime under complex loads spectra, design methodologies and materials databases are relatively well established.

Design methodologies to predict delamination between plies due to thickness-direction stresses are not well established and failures in composite structures are often initiated by delamination. Delaminations occur in areas of complex, three-dimensional stress states which are rarely analyzed in detail during design. The resistance to failure due to thickness-direction shear and normal stresses is very low relative to the fiber dominated properties along the primary load paths. Lower cost thermoset resins are brittle, and their composites have low delamination resistance.

Manufacturing problems such as resin-rich areas and porosity can provide sites for delamination initiation. Environmental factors and fatigue loading can lead to the spread of delaminations at low load levels. In aerospace applications, the delamination problem has been addressed primarily through increased resin toughness (which is costly), conservative designs in structural detail areas, and a variety of rules-of-thumb [1].

This paper addresses two aspects of the delamination problem. First, test methodologies and typical data are presented for fracture mechanics based interlaminar properties. The data are included in the current DOE/MSU composite materials fatigue database [2]. The second part of the paper demonstrates a methodology for designing structural details against delamination failure. A more detailed description of this research can be found in Reference 3, available on the Sandia web site www.sandia.gov/Renewable_Energy/Wind_Energy/.

\section{DELAMINATION RESISTANCE}

Out-of-plane stresses which cause delamination occur naturally at many types of structural details, as indicated in Figure 1 [1]. Common structural details which can produce delamination in blades are ply drops, skin-stiffener intersections, sandwich panel (balsa) closeouts, and trailing edge areas [3].

As with monolithic materials [4], delamination crack growth may be separated into three independent modes (Figure 2), with mixed-mode cracks common in many geometries. Modes I and II are the most prevalent in delamination problems, and test methods for pure Mode I and II cracks have been standardized.

Crack resistance may be represented either by the energy associated with crack growth $\left(\mathrm{G}_{\mathrm{IC}}\right.$ and $\left.\mathrm{G}_{\mathrm{IIC}}\right)$ or the 
stress intensities at the crack tips $\left(\mathrm{K}_{\mathrm{IC}}\right.$ and $\left.\mathrm{K}_{\mathrm{IIC}}\right)$. For mixed mode cracks, a combined mode criterion is needed.

Delamination in laminates is measured most conveniently in terms of the energies (G's) due to the compliant geometry associated with ply separations. Reference [6] reviews the use of fracture mechanics in composites.

\section{Delamination Testing and Analysis Methods}

Widely used tests for Modes I and II are the double cantilever beam (DCB) and end notch flexure (ENF) tests depicted in Figures 3 and 4. Composites testing of this type has led to greatly improved delamination resistance, primarily through the development of tougher resins.Test specimens are prepared by molding in a strip of teflon coated fabric as a starter crack.

For reasons discussed later, it is often necessary to measure the strain energy release rates for very short values of crack extension, called "initiation" $\mathrm{G}_{\mathrm{IC}}$ and $\mathrm{G}_{\mathrm{IIC}}$. These are usually the minimum values relative to those measured with greater lengths of crack growth. Measurement of initial crack growth requires careful observation of the crack length during testing, or loading-unloading sequences with inspection for crack length at each step. The lowest values in this study are reported for cases where the crack grew directly from the teflon starter strip with no initial pre-cracking, although other studies have shown higher values for this case for some toughened matrices, due to the matrix area at the edge of the teflon [7]. An alternative method, which is also used for unstable growth in Mode II, follows the 5 percent offset procedure used in ASTM Standard E399 for metals. Figure 5 illustrates this method as applied in ENF tests; this method was used to obtain initiation values in this study.

A wide range of analysis methods have been developed for delamination in test geometries [6]. The most widely used methods are based on modified beam theory (MBT). Equations (1) and (2) give the MBT based equation used to calculate $\mathrm{G}_{\mathrm{IC}}$ and $\mathrm{G}_{\mathrm{IIC}}$ in this study.For the Mode I, DCB specimen [8],

$$
G_{I C}=\frac{3 P \delta}{2 b a}
$$

where: $\mathrm{P}=$ critical load at crack propagation

$\delta=$ displacement between cantilever arms at critical load 
$\mathrm{b}=$ specimen width

$\mathrm{a}=$ crack length measured from the center of the load pins

For the Mode II, ENF specimen [9]:

$$
G_{I I C}=\frac{9 P^{2} a^{2} C}{2 b\left(2 L^{3}+3 a^{3}\right)}
$$

where: $\mathrm{P}=$ critical load at propagation

$$
\begin{aligned}
& \mathrm{a}=\text { crack length measured from support point of the ENF specimen } \\
& \mathrm{C}=\text { specimen compliance }(=\text { center point deflection } / \mathrm{P}) \\
& \mathrm{L}=\text { one-half support spacing distance }
\end{aligned}
$$

Several methods have been developed for use with finite element analysis (FEA) to predict strain energy relea se rates in each mode of crack extension. Two popular ways to calculate G are by (1) calculating the change in strain energy in an FEA model with an associated crack extension (virtual crack extension - VCE) [10], and (2) calculating the energy required to close a crack front by a small increment (virtual crack closure technique-VCCT). Both methods have gained acceptance, but the virtual crack closure technique has emerged as the preferred method. It has the benefit of allowing separate $G$ calculations for each mode of crack extension.

The one-step VCCT method in ANSYS FEA Software has been used in this study to calculate G values for structural details as described later. Analysis details such as mesh sensitivity for typical cases are given in Reference 3. For the test specimens, the VCCT method gave similar G-values to those calculated from equations (1) and (2).

\section{Mixed-Mode Fracture Criteria}

Mixed mode fracture criteria have been explored in a number of studies [5]. A commonly used interaction 
criterion based on the G-values which are actually measured in DCB $\left(\mathrm{G}_{\mathrm{IC}}\right)$ and $\mathrm{ENF}\left(\mathrm{G}_{\mathrm{IIC}}\right)$ delamination tests. This can be expressed in terms of fracture energies as

$$
\left(\frac{G_{I}}{G_{I C}}\right)^{\frac{m}{2}}+\left(\frac{G_{I I}}{G_{I I C}}\right)^{\frac{n}{2}}=F
$$

where the coefficients $\mathrm{m}$ and $\mathrm{n}$ are determined by curve-fitting. When $\mathrm{F}$ is greater than 1.0 , crack growth occurs. Values of $\mathrm{m}=\mathrm{n}=2$ result in a linear interaction in terms of the fracture energies. Equation 3 has been applied in this study for static delamination, and extended to fatigue crack growth by using the $G_{I}$ and $G_{I I}$ for a particular crack grow th rate, in place of the static fracture values $\mathrm{G}_{\mathrm{IC}}$ and $\mathrm{G}_{\mathrm{IIC}}$.

\section{$\underline{\text { Results and Discussion }}$}

\section{Modes of Crack Growth}

Testing for delamination resistance is often complicated by crack extension which is not self-similar. That is, the crack does not extend in a simple flat planar fashion from the starter crack which is included in the test specimen. Often, the first millimeter or two is self-similar, particularly if there is a matrix rich area ahead of the teflon film used as a starter crack. As the crack extends, the adjacent plies may form cracks in the matrix and interface above and below the delamination plane, or strands may debond from the adjacent plies, sometimes bridging the crack. These phenom ena can significantly increase the resistance to propagation of the main crack relative to a simple self-similar extension of the main crack between the plies. The interpretation of delamination resistance is greatly complicated due to these associated cracks and debonding. While this has been observed in Mode I in prepreg materials [13], it is more common the more heterogeneous the microstructure becomes. A major concern is that, in an application with mixed-mode cracks and different far-field stresses, the benefits of the secondary crack phenomena may not be realized, and the crack resistance may be much lower. The most self-similar crack growth tends to occur for short lengths of crack extension between $0^{\circ}$ plies, where the crack extends parallel to the fibers.

Schematics of crack paths from tests involving a $45^{\circ} / 90^{\circ}$ interface (the other plies are $\pm 45^{\circ}$ ) relative to the crack path are shown in Figure 6. Interfaces involving $45^{\circ}$ and $90^{\circ}$ plies show extensive secondary cracking; they are common 
in stiffener-type substructures as discussed later. The Mode I (DCB) crack contains extensive matrix cracking in the $\pm 45^{\circ}$ plies, away from the main crack (Figure 6a). In fatigue crack growth (Figure 6b) the lower stresses result in a significant reduction in secondary cracking in Mode I. This reduction in secondary cracking in fatigue has also been observed in prepreg materials [13]. In Mode II, ENF specimens (Figure 6c), reduced secondary cracking is observed, and in fatigue in Mode II (Figure 6d) no secondary cracking is observed.

\section{Test Results}

The extensive secondary cracking in Mode I results in an increasing crack resistance as the crack extends, termed Rcurve behavior [5]. Figure 7 shows the increasing value of $\mathrm{G}_{\mathrm{IC}}$ calculated as a function of the length of crack extension from the initial starter crack $\left(a^{*}=a-a_{o}\right)$. In Figure 7 , data are presented for the value of $\mathrm{G}_{\mathrm{IC}}$ measured at different amounts of crack extension from the edge of the teflon strip. The increase in $\mathrm{G}_{\mathrm{IC}}$ is substantial as the crack extending due to the increasing secondary cracking.

The values of $\mathrm{G}_{\mathrm{IC}}$ and $\mathrm{G}_{\text {IIC }}$ are both widely scattered and very sensitive to the amount of crack extension, which complicates their use in predicting delamination in structural details. To simplify delamination prediction, G-values are presented in Table 1 for initial growth (less than $2 \mathrm{~mm}$ of crack extension), as well as average values for all crack lengths. Further simplification in using these results is obtained by using only the values for cracks in $0^{\circ}$ unidirectional materials. Initial crack growth values for $0^{\circ}$ unidirectional materials provide the lowest values for $\mathrm{G}_{\mathrm{IC}}$ and $\mathrm{G}_{\text {IIC }}$, and are therefore conservative when applied to delamination interfaces between plies of other orientation. As demonstrated later, this allows simplified conservative prediction of delamination in structural details. Thus, it is only necessary to test $0^{\circ}$ unidirectional laminates with the reinforcing fabric and resin of interest in the application. The results in Table 1 also indicate a strong sensitivity of G-values to resin toughness as described in References 3 and 14.

In fatigue crack growth, the growth rate is measured only for the first five millimeters or less of crack growth. Only one crack velocity is obtained for each specimen at a particular maximum G-value. This procedure is consistent with that adopted (for similar reasons) with carbon/epoxy prepreg laminates in Reference 13 . However, fatigue crack growth cannot be reduced to initiation only, since it inherently involves crack extension over distances. 
Table 1. Mode I and II Delamination Results (Ambient Conditions).

\begin{tabular}{|c|c|c|c|c|c|}
\hline Resin & $\mathrm{V}_{\mathrm{F}}, \%$ & Crack interface & $\mathrm{G}_{\mathrm{IC}}$ initial, $\mathrm{J} / \mathrm{m}^{2}$ & $\mathrm{G}_{\mathrm{IC}}(\mathrm{ave}), \mathrm{J} / \mathrm{m}^{2}$ & $\mathrm{G}_{\mathrm{IIC}}, \mathrm{J} / \mathrm{m}^{2}$ \\
\hline Derakane 8084(V) & 36 & {$[0 / 0]$} & $344(7)$ & $595(133)$ & $2638(567)$ \\
\hline Derakane 411C50(V) & 36 & {$[0 / 0]$} & 234 & 396 & 2557 \\
\hline System 41(E) & 36 & {$[0 / 0]$} & $219(22)$ & $231(38)$ & 3776 \\
\hline SC-14 (E) & 36 & {$[0 / 0]$} & $638(58)$ & $638(157)$ & $3223(520)$ \\
\hline Iso-polyester 75-AQ-010 & 36 & {$[0 / 0]$} & $200(23)$ & $321(96)$ & $1359(459)$ \\
\hline \multirow{5}{*}{$\begin{array}{c}\text { Ortho-polyester } \\
\text { 63-AX-051 (P) }\end{array}$} & 40 & {$[0 / 0]$} & $153(10)$ & $196(99)$ & $977(229)$ \\
\cline { 2 - 6 } & 40 & {$[0 / 0]$} & ---- & $490(3)$ & $1430(35)$ \\
\cline { 2 - 6 } & 40 & {$[+45 /-45]$} & ---- & $780(4)$ & $2270(53)$ \\
\cline { 2 - 6 } & 36 & {$[0 / 0]$} & $138(56)$ & $379(81)$ & $1293(259)$ \\
\cline { 2 - 6 } & 35 & {$[45 / 45]$} & $249^{1}(75)$ & $462(107)$ & $2001(286)$ \\
\hline
\end{tabular}

NOTE: values in ( )'s indicate the standard deviation. $0^{\circ}$ and $90^{\circ}$ fabrics were D 155 and $45^{\circ}$ fabrics were DB 120 , both from Owens Corning Fabrics, except as noted.

${ }^{1}$ The average initiation $\mathrm{G}_{\mathrm{IC}}$ from the starter strip was $236 \mathrm{~J} / \mathrm{m}^{2}$.

2 The average initiation $\mathrm{G}_{\mathrm{IC}}$ from the starter strip was $191 \mathrm{~J} / \mathrm{m}^{2}$.

${ }^{3}$ Using UC1018V unidirectional fabric (Collins Craft).

\section{Fatigue Crack Growth}

The complications evident in the delamination results for static tests (R-curve behavior, broad scatter) are also present in the important situation where delamination cracks extend during service as a result of fatigue. Since the Glevels are lower in fatigue, the extent of secondary cracking is also usually lower (Figure 6). For practical reasons, cracks must extend for at least a few mm for measurements to be made.

The fatigue crack growth data (Figures 8 and 9) are represented in terms of the Paris Law, Equation 4 [5]. These data are similar in nature to those for prepreg based materials in the literature, in terms of crack growth exponent, n, where

$$
\frac{d a}{d N}=A(\Delta G)^{n}
$$

and $\mathrm{A}$ is a constant. It should be noted that it is often impossible to obtain self-similar crack extension in the desired ply interface, as cracks migrate to other interfaces, particularly in fatigue [3]. 
It is possible to measure fatigue crack growth down to a range of about 20 percent of $\mathrm{G}_{\mathrm{C}}$, where the growth rate is on the order of $10^{-6}$ to $10^{-7} \mathrm{~mm} / \mathrm{cycle}$. Other studies using similar materials [ 15 ] have shown a threshold in this range of $\mathrm{G}_{\mathrm{MAX}} / \mathrm{G}_{\mathrm{C}}$ below which no crack crack growth occurred. As a practical matter for design, it can be assumed that no delamination will occur if $\mathrm{G}_{\mathrm{I}} / \mathrm{G}_{\mathrm{IC}}$ or $\mathrm{G}_{\mathrm{II}} / \mathrm{G}_{\mathrm{IIC}}$ or their interaction term $\mathrm{F}$ (Equation 3) are below 0.1 to 0.2 as explored later for structural details. As with the static case, it is conservative to consider only $0^{\circ}$ unidirectional cases with the fabric and resin of interest, and small values of crack extension $(<5 \mathrm{~mm})$.

\section{DELAMINATION OF SKIN-STIFFENER INTERSECTION}

The methodology pursued in this work is based on the use of ANSYS [16] based finite element analysis of the structural detail of interest, with cracks inserted in areas of high stress gradients. $\mathrm{G}_{\mathrm{I}}$ and $\mathrm{G}_{\mathrm{II}}$ values are then determined using the VCCT-1 method. Comparisons with database static and fatigue G-values, with appropriate load scaling, produces a predicted load for delamination. This load is compared with experimental values to validate the process.

\section{$\underline{\text { Experimental Methods }}$}

The skin-stiffener specimens shown in Figure 10 were constructed of fabrics D 155 for $0^{\circ}$ and $90^{\circ}$ layers and

DB120 for the $\pm 45^{\circ}$ layers. This specimen has been used to rate structural integrity for various resins in earlier studies $[3,15]$. Most of the study used the CoRezyn 63-AX-051 ortho polyester with 1 to 2 percent MEKP catalyst. Other resins studied for comparison were isophthalic polyester and Derakane 411C-50 and 8084 vinyl ester. All materials were resin transfer molded and post cured at $60^{\circ} \mathrm{C}$ for two hours. The layup of the laminate was $\left[\left( \pm 45 / 0_{2} / \pm 45\right)\right] \mathrm{s}$, where $0^{\circ}$ is normal to the plane of Figure 10. More details of the geometry can be found in Reference 3 .

\section{$\underline{\text { Static and Fatigue Tests }}$}

The test set-up is shown in Figure 11. Static tests were run by loading the top of the specimen at a constant 
displacement rate of $0.25 \mathrm{~mm}$ per second, yield ing forc e-displacem ent curves similar to Figure 12, allowing identification of the initial damage load and the maximum load sustained. Fatigue tests were run at a low frequency of 2 to $4 \mathrm{~Hz}$ and an R-value of 0.1 , with a sinusoidal waveform. Data for displacement, force, and strain in the skin were recorded periodically. The strain in the skin was measured with an extensometer positioned as shown in Figure 12. The specimens were inspected for damage by stopping tests after every $0.635 \mathrm{~mm}$ increase in the maximum displacement. Tests were continued until the maximum displacement increased by $5 \mathrm{~mm}$ compared with the first cycle, which corresponds to the range observed for initial damage development in static tests.

\section{Numerical Methods and Failure Criteria}

The delamination and skin-stiffener geometries were modeled using ANSYS FEA software [16]; input elastic constants are given in Reference 3. A plane strain analysis employing ANSYS plane-82 quadrilateral elements was used in the skin-stiffener models, which were also constructed using individual lamina layers and not smeared laminate properties. Half-symmetry about the web of the stiffener was employed to simplify the model by restricting the nodes along the mid-line to have zero X-displacement. Details of the coordinate system and modelling assumptions can be found in Reference 3.

The FE model was first run without damage, to determine sites of likely damage development. Based on these results, a small delamination crack was inserted in the bend region, where failure was predicted from the first model. The model with a crack was then used to determine $\mathrm{G}_{\mathrm{I}}$ and $\mathrm{G}_{\mathrm{II}}$ values at the crack tips. These values were then used to predict static and fatigue loads for delamination growth.

Initial crack development is highlighted in the micrograph of Figure 13, and developed fatigue damage (and the sequence of cracking) is indicated in the schematic, Figure 14. The finite element mesh and tangential strains are shown in Figure 15 for the geometry including the assumed delamination crack.

\section{$\underline{\text { Results and Discussion }}$}

\section{Static Delamination}

The experimental initial damage load, crack length (Figure 12), and critical load for extension of the crack are 
given in Table 2 for the ortho-polyester resin system. Table 3 compares static initial damage load and maximum load for skin-stiffener specimens as well as $\mathrm{G}_{\mathrm{IC}}$ and $\mathrm{G}_{\mathrm{IIC}}$ for $0^{\circ}$ laminates using four resins. The tougher resins (higher $\mathrm{G}_{\mathrm{IC}}$ and $\mathrm{G}_{\mathrm{IIC}}$ ) produce greater structural integrity in the skin-stiffener specimen, consistent with earlier findings $[3,14]$ for other resins.

The initial crack (at the observed average length of $2.8 \mathrm{~mm}$ ) was inserted in the FEA model, and $\mathrm{G}$ values were calculated for a particular load P model for the crack tips. Using Equation 3, the value of P was determined using different values of $\mathrm{n}$ and $\mathrm{m}$. The critical load for delamination growth was then calculated from

$$
\mathrm{P}_{\mathrm{CR}}=(1 / \mathrm{F})^{1 / 2} \mathrm{P}_{\text {model }}
$$

Table 2. Static Load and Crack Length Data for Ortho-Polyester Skin-Stiffeners (6 total tests); Parentheses indicate the standard deviation.

\begin{tabular}{|c|c|c|}
\hline \multicolumn{2}{|c|}{ Initial Damage } & Critical load for crack growth, N/cm \\
\hline Load, N/cm & Crack length, mm & $129(8)$ \\
\hline $94.9(6.8)$ & $2.48(0.2)$ & . \\
\hline
\end{tabular}

Table 3. Average Load and Displacement Data for Different Resins in the Skin-Stiffener Geometry. Parentheses indicate the standard deviation.

\begin{tabular}{|c|c|c|c|c|c|}
\hline Matrix & $\begin{array}{c}\text { Initial damage } \\
\text { load, N/cm }\end{array}$ & $\begin{array}{c}\text { Displacement at initial } \\
\text { damage load, } \mathrm{cm}\end{array}$ & $\begin{array}{c}\text { Ultimate load, } \\
\mathrm{N} / \mathrm{cm}\end{array}$ & $\begin{array}{c}\text { Initiation } \mathrm{G}_{\mathrm{IC}} \\
\left(\mathrm{J} / \mathrm{m}^{2}\right)\end{array}$ & $\mathrm{G}_{\text {IIC }}\left(\mathrm{J} / \mathrm{m}^{2}\right)$ \\
\hline Ortho-polyester & $87.0(5.9)$ & $0.22(0.02)$ & $144(2)$ & 153 & 977 \\
\hline Iso-polyester & $98.2(2.2)$ & $0.24(0.01)$ & $166(1)$ & 200 & 1359 \\
\hline 411 vinyl ester & $144(61)$ & $0.44(0.24)$ & $198(1)$ & 234 & 2557 \\
\hline 8084 vinyl ester & $189(26)$ & $0.48(0.08)$ & $221(11)$ & 344 & 2638 \\
\hline
\end{tabular}

The basis for Equation 5 is that $\mathrm{G}$ values vary with load squared, which was confirmed by FEA runs at various loads [3].

As the structure containing the initial crack in Figure 14 was loaded for the second time, the upper crack front (crack front \#2) grew toward the web in the $0^{\circ} / 45^{\circ}$ interface. The lower crack front (crack front \#1) grew transversely through the $0^{\circ}$ ply and arrested. Similar delamination locations and growth for ortho-polyester skin-stiffeners were reported in a related study [3]. Note that the crack front $\# 2$ is in the $0^{\circ} / 45^{\circ}$ interface, but growing in the $90^{\circ}$ direction. 
This corresponds to an ENF or DCB test with the crack in a $90^{\circ} / 45^{\circ}$ interface (see delamination section).

The formation of the initial crack was predicted using the FEA model without a crack present. Table 4 compares the experimental initial damage load with the predicted value from a maximum strain failure criteria. Agreement is acceptable.

Table 4. Comparison of Predicted Initial Damage Load Using the Maximum Strain Criterion with Experimental Data for the $45^{\circ}$ Ply Interface.

\begin{tabular}{|c|c|c|}
\hline $\begin{array}{c}\text { Maximum strain } \\
\text { criterion initial } \\
\text { damage load, N/cm }\end{array}$ & $\begin{array}{c}\text { Average } \\
\text { experimental initial } \\
\text { damage load, N/cm }\end{array}$ & $\begin{array}{c}\text { Percent } \\
\text { difference }\end{array}$ \\
\hline 82.6 & 94.9 & 13 \\
\hline
\end{tabular}

Results are presented in Table 5 for the predicted and experimental loads for delamination growth, using two methods. Using $\mathrm{m}$ and $\mathrm{n}$ values of 2 and 1 in Equation 3, and the R-curve $\mathrm{G}_{\mathrm{IC}}$ value at the crack extension of $2.48 \mathrm{~mm}$ (Method A), the interaction sums F were 0.56 and 0.98 respectively, shown in Table 5 . This resulted in predicted crack propagation loads of 173 and $130 \mathrm{~N} / \mathrm{cm}$ respectively. This analysis shows that exponents of $\mathrm{m}=\mathrm{n}=1$ seem to correlate well with the experimental data. A difference of 1.2 percent from the experimental critical propagation load of $129 \mathrm{~N} / \mathrm{cm}$ was obtained with exponents $m=n=1$, compared to a difference of 34 percent with ratio exponents of $m=n=2$. However, as noted earlier, the DCB $\mathrm{G}_{\mathrm{IC}}$ of $342 \mathrm{~J} / \mathrm{m}^{2}$ was taken from an R-curve (Figure 7) at the observed $2.48 \mathrm{~mm} \mathrm{crack}$ extension. Had the initiation $\mathrm{G}_{\mathrm{IC}}$ values from the DCB tests, ranging from 132 to $261 \mathrm{~J} / \mathrm{m}^{2}$, with an average of $191 \mathrm{~J} / \mathrm{m}^{2}$, been used, the prediction with $\mathrm{m}=\mathrm{n}=2$ would have been much closer. If, as in Table 5 , crack extensions up to $2 \mathrm{~mm}$ were allowed for the initiation $\mathrm{G}_{\mathrm{IC}}$, the average value would increase to $273 \mathrm{~J} / \mathrm{m}^{2}$. Thus, the use of R-curve values to represent initial crack growth in a substructure may not be justified.

If a conservative initiation value of $\mathrm{G}_{\mathrm{IC}}$ is used, taken as the $\mathrm{G}_{\mathrm{IC}}$ for initiation in a $0^{\circ} / 0^{\circ}$ interface (Method $\left.\mathrm{B}\right)$, then values of $m=n=2$ in Equation 3 are appropriate. the choice of $G_{I C}$ definition from DCB tests is particularly sensitive for interfaces containing a $90^{\circ} \mathrm{ply}$, as noted in the delamination section. Thus, if the $\mathrm{G}_{\mathrm{IC}}$ for initiation in a $0^{\circ} / 0^{\circ}$ interface is used, good agreement is found for the force prediction using $m=n=2$ in Equation 3. This agrees with the observed crack in the T-section (Figure 14), which shows no secondary cracking, like a $0^{\circ} / 0^{\circ}$ interface. Method $\mathrm{B}$ is recommended due 
to its conservative approach and reduced data requirements (tests need not be run for every interface combination).

Table 5. Static G-Values, Interaction Sums and Predicted Critical Loads for the FEA Skin-Stiffener Model. Method A uses $\mathrm{G}_{\mathrm{IC}}$ from R-curve data at a crack length of $2.48 \mathrm{~mm}$; Method B uses $\mathrm{G}_{\mathrm{IC}}$ initiation data for a $0^{\circ} / 0^{\circ}$ Interface.

\begin{tabular}{|c|c|c|c|}
\hline & & Method A & Method B \\
\hline \multirow{2}{*}{$\mathrm{G}_{\mathrm{IC}}$ and $\mathrm{G}_{\mathrm{IIC}}$ from DCB and ENF Tests } & $\mathrm{G}_{\mathrm{IC}}, \mathrm{J} / \mathrm{m}^{2}$ & 341.8 & 138 \\
\hline & $\mathrm{G}_{\mathrm{IIC}}, \mathrm{J} / \mathrm{m}^{2}$ & 941.3 & 1293 \\
\hline \multirow{2}{*}{$\mathrm{G}_{\mathrm{I}}$ and $\mathrm{G}_{\mathrm{II}}$ at the critical load from FEA } & $\mathrm{G}_{\mathrm{I}}, \mathrm{J} / \mathrm{m}^{2}$ & 143.1 & 143.1 \\
\hline & $\mathrm{G}_{\mathrm{II}}, \mathrm{J} / \mathrm{m}^{2}$ & 101.4 & 101.4 \\
\hline \multicolumn{2}{|c|}{ Experimental critical load, N/cm } & 128.6 & 128.6 \\
\hline \multicolumn{2}{|l|}{$\mathrm{F}$ for $\mathrm{m}=\mathrm{n}=2($ Equation 3$)$} & 0.56 & 1.12 \\
\hline \multicolumn{2}{|c|}{ Predicted critical load, N/cm } & 172.6 & 122 \\
\hline \multicolumn{2}{|l|}{$\mathrm{F}$ for $\mathrm{m}=\mathrm{n}=1($ Equation 3$)$} & 0.98 & 1.30 \\
\hline \multicolumn{2}{|c|}{ Predicted critical load, N/cm } & 130.2 & 113 \\
\hline
\end{tabular}

Good agreement was also found using the same approach for a related validation study [3], where a similar geometry to Figure 11 was used, but with a much thicker flange (Figure 16). Here, a flaw was introduced at the corner of the flange without a prior strength analysis since it was an obvious stress concentration area. Table 6 shows that the failure load was predicted with good accuracy.

\section{Fatigue Delamination}

The same skin-stiffener model was used to predict behavior for the fatigue loading tests. Figure 17 gives the fatigue crack growth data measured for the skin-stiffener specimen, expressed as $\mathrm{G}_{\mathrm{I}}$ and $\mathrm{G}_{\mathrm{II}}$ components derived from the FEA at the experimental loads. Experimental observations showed that delaminations occurred in the $0^{\circ} / 45^{\circ}$ interface. The non-symmetric model was analyzed with various crack lengths to investigate the mode interaction as crack front \#2 propagated toward the web. Crack lengths in the fatigue model were varied from $1.2 \mathrm{~mm}$ to $9.0 \mathrm{~mm}$ to determine mode interactions for various crack lengths in the bend region [3].

A similar methodology to that used to predict critical static loads was used to determine the cyclic crack growth rate of the skin-stiffeners at a specified load level. Three specific experimental cases were investigated that were run at various load levels resulting in various crack growth rates $(\mathrm{da} / \mathrm{dN})$. 
The DCB and ENF G-values were obtained from the inverse of the power law curve-fit Equation 4 (Figures 8 and 9) relating $\mathrm{G}$ and $(\mathrm{da} / \mathrm{dN})$ for the DCB and ENF specimens. In Equation 3, if the sum of the two ratios $\mathrm{F}$ is equal to one, it is assumed that crack growth will occur at the chosen rate $(\mathrm{da} / \mathrm{dN})$. Since $\mathrm{G}$ is proportional to $\mathrm{P}^{2}$, the load can be scaled by F to obtain the predicted load for the selected growth. Ratio sums F, predicted load, crack length, crack growth rate and experimental load are presented in Table 7.

When the normalized $\mathrm{G}_{\mathrm{I}}$ and $\mathrm{G}_{\mathrm{II}}$ components of the skin-stiffener are compared to the individual mode tests (DCB and ENF), the Mode II -G components (Figures 9 and 17) possess similar slopes but very different $\mathrm{G}_{\mathrm{II}} \mathrm{values}$ The Mode I - G component (Figure 17) of the stiffener gives approximately half the exponent of the DCB Mode I test, but the $\mathrm{G}_{\mathrm{I}}$ values are closer together than are the $\mathrm{G}_{\mathrm{II}}$ values. These discrepancies may be due to geometric effects since the stiffener crack is in the bend region. The interaction term $(\mathrm{F})$ which correlates the data best is $0.5(\mathrm{~m}=\mathrm{n}=1)$, the same as for the static case using R-curve values (Method A).

The method described above is, as in the static case, complicated by use of growing cracks with secondary cracking in some cases. This is difficult to avoid with fatigue cracks, where true initiation values are difficult to establish. A more simple and conservative approach (fatigue Method B) is to base substructure design on threshold values for fatigue crack growth. Figures 8 and 9 show that threshold values of $\mathrm{G}_{\mathrm{IC}} / 10$ and $\mathrm{G}_{\mathrm{IIC}} / 10$ would fall below the data for the slowest crack growth which could be measured. This is also consistent with threshold data in References 13 and 15 . As in Method B for the static case (Table 5), where $\mathrm{G}_{\mathrm{IC}}$ and $\mathrm{G}_{\mathrm{IIC}}$ were taken as initiation values for cracks in $0^{\circ} / 0^{\circ}$ interfaces, this method, using $\mathrm{G}_{\mathrm{IC}}$ and $\mathrm{G}_{\text {IIC }}$ values for a $0^{\circ} / 0^{\circ}$ interface (Table 8 ) and $\mathrm{m}=\mathrm{n}=2$, using Equation 3 , predicts a load of $38.6 \mathrm{~N} / \mathrm{cm}$ for no fatigue crack extension (Table 8). This is well below the experimental load for the slowest cracks observed (Table 7) of $61.3 \mathrm{~N} / \mathrm{cm}$, and is about 30 percent of the experimental static crack growth load. This appears to be a practical method of fatigue design against delamination in structural details. A higher value like $\mathrm{G}_{\mathrm{IC}} / 5$ and $\mathrm{G}_{\text {IIC }} / 5$ might be more accurate, and appears to be justified for fabric type structures [15]; this would give a critical load of 54.5 $\mathrm{N} / \mathrm{cm}$, which is less conservative. An adjustment to Equation 5 for this case is:

$$
F_{F}=\frac{G_{I C} /(5 \text { or } 10)}{G_{I} \text { model }}+\frac{G_{I C} /(5 \text { or } 10)}{G_{I I} \text { model }}
$$


where:

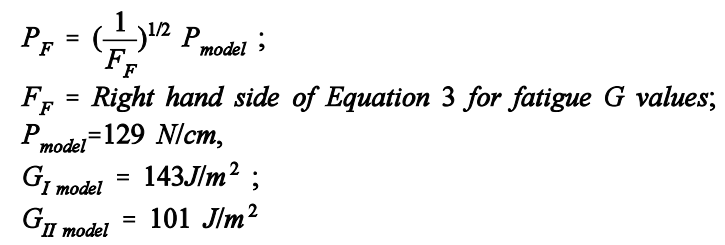

and $P_{\text {model }}$ is the static experimental load for delamination, $G_{\text {Imodel }}$ and $G_{\text {IImodel }}$ are the FEA values at this load. Alternately, any load applied to the model containing a crack could be used, with FEA values for $\mathrm{G}_{\mathrm{I}}$ and $\mathrm{G}_{\mathrm{II}}$. Fatigue Method B with $\mathrm{G}_{\mathrm{IC}} / 5$ and $\mathrm{G}_{\mathrm{IIC}} / 5$ is recommended for its simplicity and conservative predictions.

\section{$\underline{\text { Fatigue Lifetime with Different Resins }}$}

Skin-stiffeners were tested in fatigue with the additional three resin systems (see Table 3 for static data). Damage initiation was similar in mode for all of the systems tested. All cracks formed in the $0^{\circ} / 45^{\circ}$ interface and propagated in a manner similar to the fatigue crack growth in the ortho-polyester stiffeners. The criterion used for specimen failure was defined as reaching a maximum cyclic deflection of $0.43 \mathrm{~cm}$. This was the displacement for initial damage for the static ortho-polyester skin-stiffener specimens. Thus, the lifetimes given are for a displacement failure criterion which correlates with damage development, as confirmed experimentally for each system.

The maximum cyclic load versus number of cycles to failure is plotted for each of the matrix materials in Figure 18. The vinyl esters operated at the highest maximum loads to equivalent cycles to failure when compared to the three other matrix materials. The 8084 vinyl ester produced the largest initial and maximum loads during the static load tests, and also performed the best on an absolute load scale during fatigue testing. 
Table 6. Initial Damage Load Predictions versus Experimental Data for a Crack at the Flange Tip of a Thick-Flange Specimen.

\begin{tabular}{|c|c|c|c|c|c|c|}
\hline \multirow{2}{*}{$\begin{array}{c}\text { Specimen } \\
\text { Ratio } \\
(\mathrm{a} / \mathrm{da})\end{array}$} & $\begin{array}{c}\text { FEA Crack } \\
\text { Length }(\mathrm{a}, \mathrm{mm})\end{array}$ & \multicolumn{2}{|c|}{$\begin{array}{c}\text { Experimental Fracture } \\
\text { Onset, N/cm }\end{array}$} & $\begin{array}{c}\text { VCCT -1 } \\
\text { Prediction, } \\
\mathrm{N} / \mathrm{cm}\end{array}$ & $\begin{array}{c}\text { Percent Difference in } \\
\text { Predicted Fracture Load }\end{array}$ \\
\cline { 4 - 6 } $\begin{array}{c}\text { T5200 } \\
{\left[0^{\circ} / 0^{\circ}\right] \text { interface }}\end{array}$ & 26 & 0.201 & 153 & 8 & 141 \\
$+25.9 /-32.4$ & Std. Dev. & -7.4 \\
\hline
\end{tabular}

Table 7. Experimental and Predicted Loads for Different Crack Growth Rates in the Bend Region of Cyclic Loaded SkinStiffeners.

\begin{tabular}{|c|c|c|c|c|c|c|c|}
\hline \multirow{2}{*}{ Specimen } & \multirow{2}{*}{ Crack length, mm } & \multirow{2}{*}{$\begin{array}{c}\mathrm{da} / \mathrm{dN}, \\
\mathrm{mm} / \text { cycle }\end{array}$} & \multicolumn{2}{|c|}{ Ratio sum (F) } & \multirow{2}{*}{$\begin{array}{l}\text { Experimental } \\
\text { load, } \mathrm{N} / \mathrm{cm}\end{array}$} & \multirow{2}{*}{$\begin{array}{c}\text { Predicted load, N/cm, } \\
(\mathrm{m}, \mathrm{n}=0.5)\end{array}$} & \multirow{2}{*}{$\begin{array}{c}\text { error, } \\
\%\end{array}$} \\
\hline & & & $\mathrm{m}, \mathrm{n}=1$ & $\mathrm{~m}, \mathrm{n}=0.5$ & & & \\
\hline 9T9 & 2.4 & $8.09 \times 10^{-7}$ & 0.57 & 1.04 & 61.3 & 60.1 & 2.0 \\
\hline $10 \mathrm{~T} 3$ & 2.8 & $9.47 \times 10^{-5}$ & 0.66 & 1.09 & 78.8 & 75.5 & 4.2 \\
\hline $10 \mathrm{~T} 3$ & 2.9 & $6.31 \times 10^{-5}$ & 0.64 & 1.10 & 78.8 & 75.1 & 4.6 \\
\hline
\end{tabular}

Table 8. Results of Simplified Method B for Prediction of Conservative Load for Safe Fatigue Design.

\begin{tabular}{|l|l|}
\hline $\mathrm{G}_{\mathrm{IC}}\left(\mathrm{DCB}, 0^{\circ} / 0^{\circ}\right.$ Interface Initiation Value $), \mathrm{J} / \mathrm{m}^{2}$ & 138 \\
\hline $\mathrm{G}_{\mathrm{IIC}}\left(\mathrm{ENF}, 0^{\circ} / 0^{\circ}\right.$ Interface Initiation Value $), \mathrm{J} / \mathrm{m}^{2}$ & 1293 \\
\hline $\mathrm{G}_{\mathrm{IC}} / 10, \mathrm{~J} / \mathrm{m}^{2}$ & 13.8 \\
\hline $\mathrm{G}_{\mathrm{IIC}} / 10, \mathrm{~J} / \mathrm{m}^{2}$ & 129.3 \\
\hline Predicted Load, N/cm & 38.6 \\
\hline $\mathrm{G}_{\mathrm{IC}} / 5, \mathrm{~J} / \mathrm{m}^{2}$ & 27.6 \\
\hline $\mathrm{G}_{\mathrm{IIC}} / 5, \mathrm{~J} / \mathrm{m}^{2}$ & 258.6 \\
\hline Predicted Load, N/cm & 54.5 \\
\hline Lowest experimental load where fatigue crack growth is observed, N/cm & 61.3 \\
\hline
\end{tabular}

\section{CONCLUSIONS}

This paper reports on a study which represents the first complete attempt in this program to predict initial cracking and delamination failure in a complex structural detail under both static and fatigue loading. The use of a 
commercial finite element code combined with basic strength data for damage initiation and fracture and fatigue crack growth data for delamination yields predictions for the load carrying capability of the structural detail which are in substantial agreement with experimental data. The simplified Method B approach for both static and fatigue predictions is recommended, as it requires less experimental data, is easier to apply, and is generally conservative.

In terms of materials selection, the results for static and fatigue testing of skin-stiffener specimens with four matrix materials lead to clear conclusions. Resins with improved interlaminar toughness produce skin-stiffener specimens with greater resistance to damage development and failure under static loading; these results for new batches of material and more consistent material thicknesses confirm the results published earlier [14]. In fatigue, the tougher resins also

perform better; however, the data tend to converge at higher cycles, so the static advantages of the tougher systems is gradually lost; this is consistent with other fatigue studies using toughened resins.

\section{REFERENCES}

1. U. S. Department of Defense, "The Composite Materials Handbook," MIL-17 Mil-HDBK-17-1F, January, 1997.

2. Mandell, J.F. and Samborsky, D.D., "MSU/DOE W ind Turbine Blade Composite Material Fatigue Database," November 1995, Sandia National Laboratories, Albuquerque, NM, 87185. Updates available at www.sandia.gov/Renewable_Energy/wind_energy/other/973002upd02.pdf

3. Mandell, J. F., Samborsky, D. D., and Cairns, D.S., "Fatigue of Composite Materials and Substructures for Wind Turbine Blades", Contractor Report SAND2002-0771, Sandia National Laboratories, Albuquerque, NM (2002).

4. Broek, D., "Elementary Engineering Fracture Mechanics," 4th Edition, Kluwer Academic Publishers, 1986. 
5. Reeder, J.R., in Composite Materials: Testing and Design (Eleventh Volume), ASTM STP 1206 , E. T. Camponeschi, Jr., Ed., American Society for Testing and Materials, Philadelphia, 1993, pp. 303-322.

6. Friedrich, K., ed., "Composite Materials Series, Vol. 6, Application of Fracture Mechanics to Composite Materials," R.B. Pipes, Series ed., Elsevier, New York (1989).

7. Davies, P. and Benzeggagh, M.L., in "Composite Materials Series, Vol. 6, Application of Fracture Mechanics to Composite Materials, K. Friedrich, ed., Elsevier, New York (1989).

8. Russell, A.J., and Street, K.N., in Delamination and Debonding, ASTM STP 876, W.S. Johnston, Ed., American Society for Testing and Materials, Phil., 1986, pp. 349-370.

9. Russell, A.J., Street, K.N., in Delamination and Debonding of Materials, ASTM STP 876, W. S. Johnson, Ed., American Society for Testing and Materials, Philadelphia, 1985, pp. 349-370.

10. Cairns, D.S., ASTM Journal of Composites Technology and Research, Vol. 14, No. 1, Spring 1992 , pp. $37-42$.

11. Mignery, L.A., Tan, T.M., Sun, C.T., in Delamination and Debonding, ASTM STP 876, W. S. Johnson, Ed., American Society for Testing and Materials, Philadelphia, 1985, pp. 371-385.

12. Hyer, M.W., Cohen, D., Proceedings of the 28th AIAA/ASME/ASCE/AHS Structures, Structural Dynamics, and Materials Conference, AIAA, Washington, DC, April 1987.

13. Mandell, J.F, and Tsai, J.Y., "Effects of Porosity on Delamination of Resin Matrix Composites," Report WRTC-TR-89-3032, Flight Dynamics Laboratory, Wright Patterson Air Force Base, Ohio (1990). 
14. Mandell, J.F., Samborsky, D.D., Li. M., Orozco, R., and Cairns, D.S., Wind Energy 2000, AIAA-2000-0057, ASME/AIAA, pp. 354-366. (2000)

15. Bathias, C. and Laksimi, A., "Delamination and Debonding of Materials," AST M STP 876, W .S. Johnson, Ed., ASTM, Phil. (1985), pp. 217-237.

16. "Volume I, Procedures, Chapter 3 Structural Analysis, Section 3.9 Fracture Mechanics," ANSYS User's Manual, pp. 3-163. 


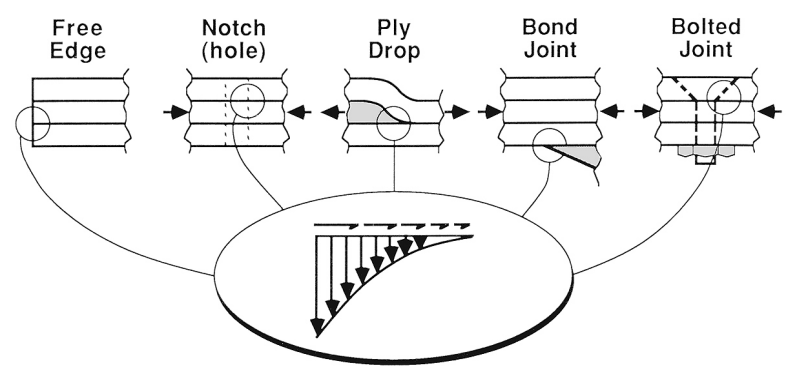

Figure 1. Common Structural Elements which Generate Interlaminar Stress Concentrations [1].
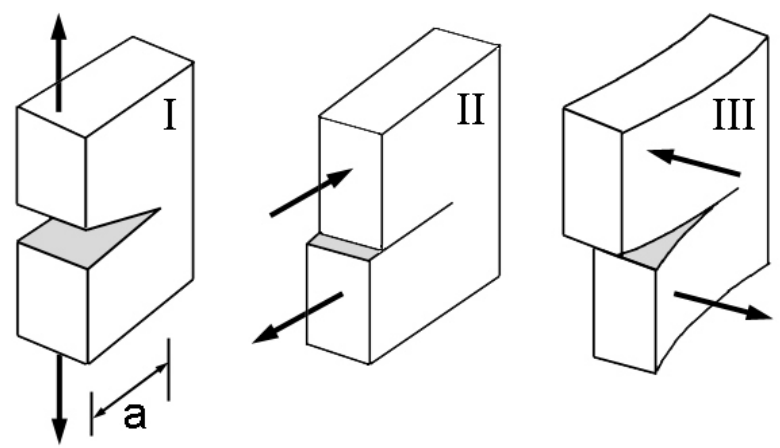

Figure 2. The Three Modes of Cracking, Mode I

(opening), Mode II (sliding) and Mode III (tearing). [4]

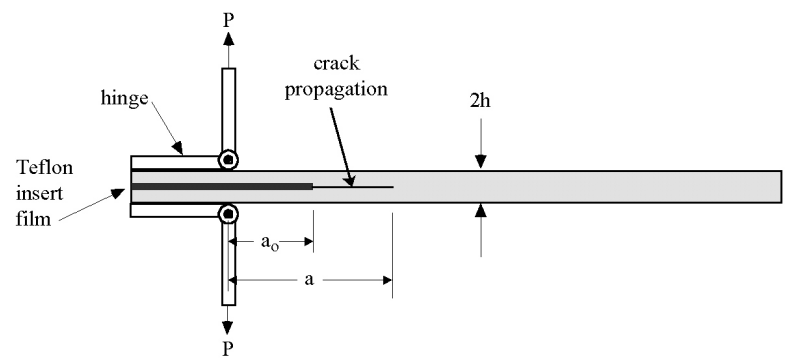

Figure 3. Mode I DCB geometry and loading (ASTM D 5528).

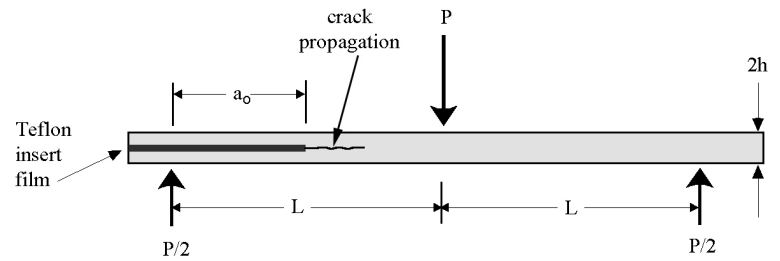

Figure 4. Mode II ENF geometry and loading. 


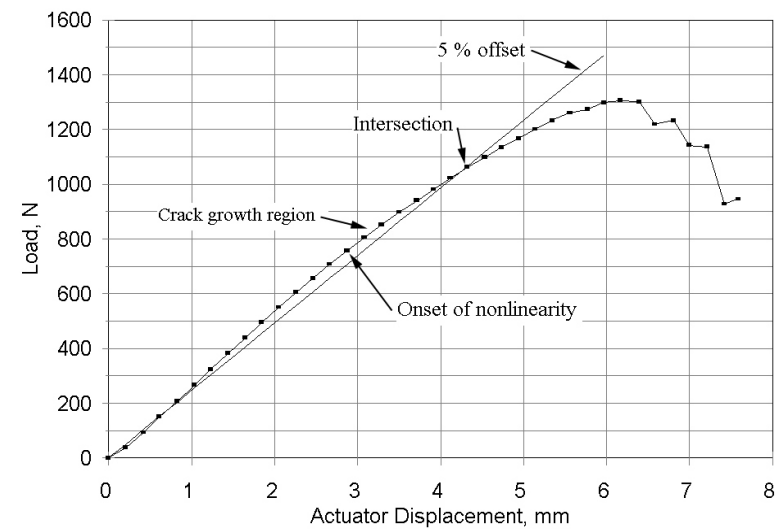

Figure 5. Typical Load versus Actuator Displacement for an ENF Specimen.
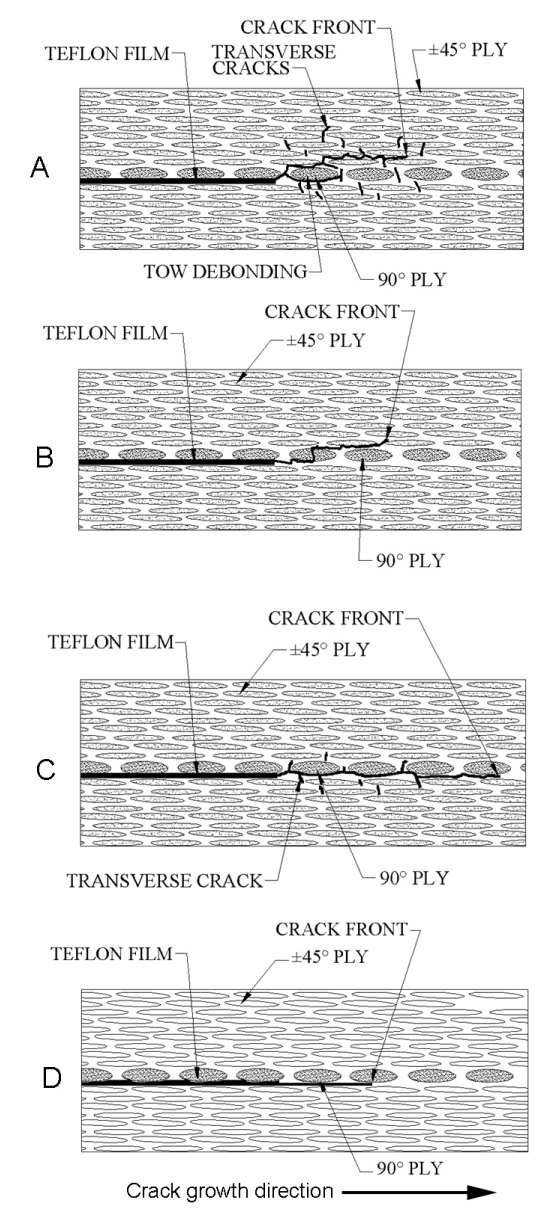

Figure 6. Sketches of Actual Observations of Crack Growth in a $\left(90^{\circ} / 45^{\circ}\right)$ Interface Under (a) Static DCB Testing, (b)Fatigue DCB Testing, (c) Static ENF Testing and (d) Fatigue ENF Testing [3]. 


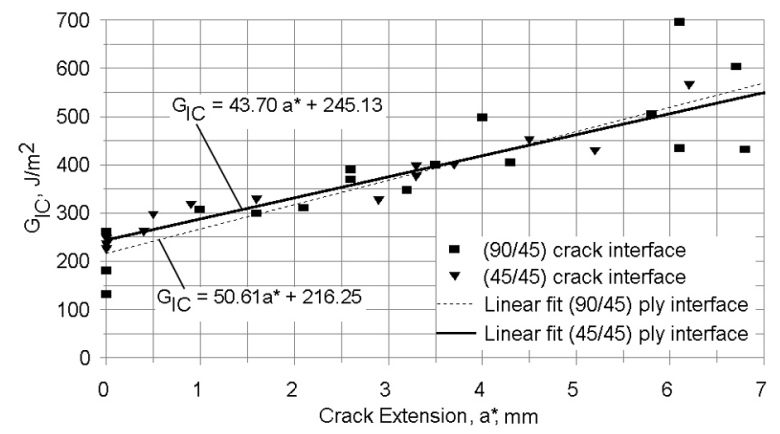

Figure 7. R-Curve Data for $(+45 /+45)$ and (90/45) interfaces, calculated with Equation (1).

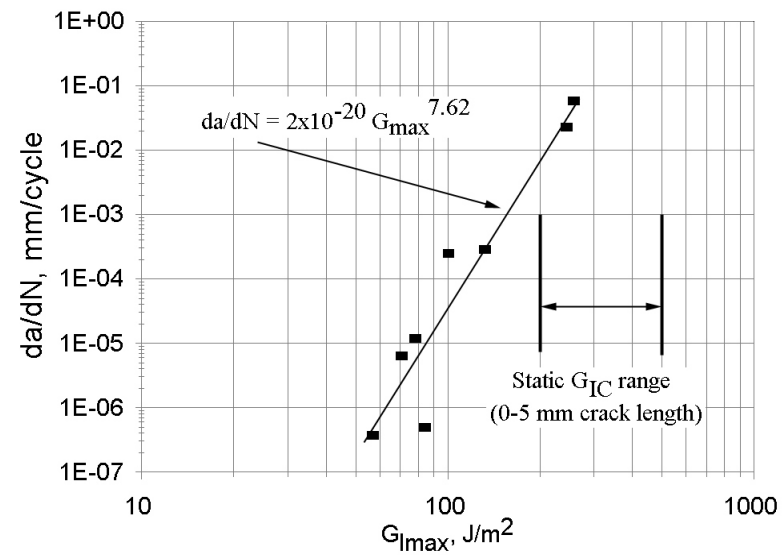

Figure 8. Mode I - $(\mathrm{da} / \mathrm{dN})$ versus $\mathrm{G}_{\text {Imax }}$.

$\left[( \pm 45)_{9} / 90 /( \pm 45)_{8}\right]$ Laminates Cracked in the $(90 / 45)$ interface. Short Crack Data (less than $5 \mathrm{~mm}$ ), $\mathrm{R}=0.1$, DCB Specimens.

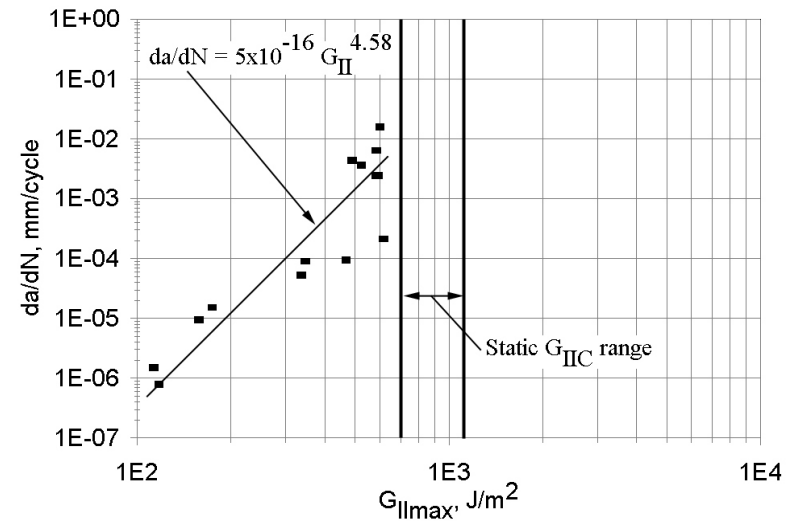

Figure 9. Mode II - $(\mathrm{da} / \mathrm{dN})$ versus $\mathrm{G}_{\text {IImax }}$.

$\left[( \pm 45)_{9} / 90 /( \pm 45)_{8}\right]$ Laminates Cracked in the $(90 / 45)$ interface, $\mathrm{R}=0.1$, ENF Specimens. 


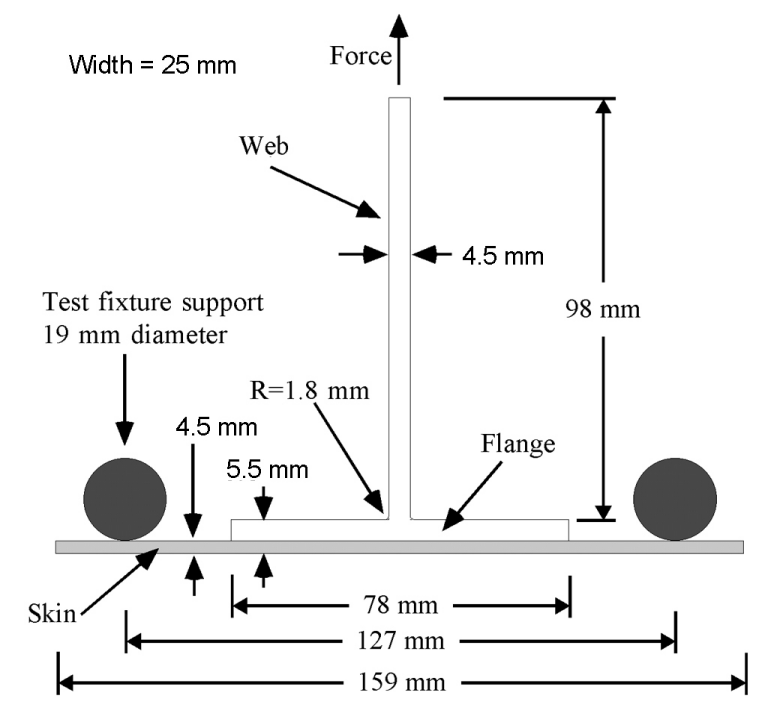

Figure 10. Standard (Thin Flange) Skin-Stiffener Loading, Geometry and Dimensions.

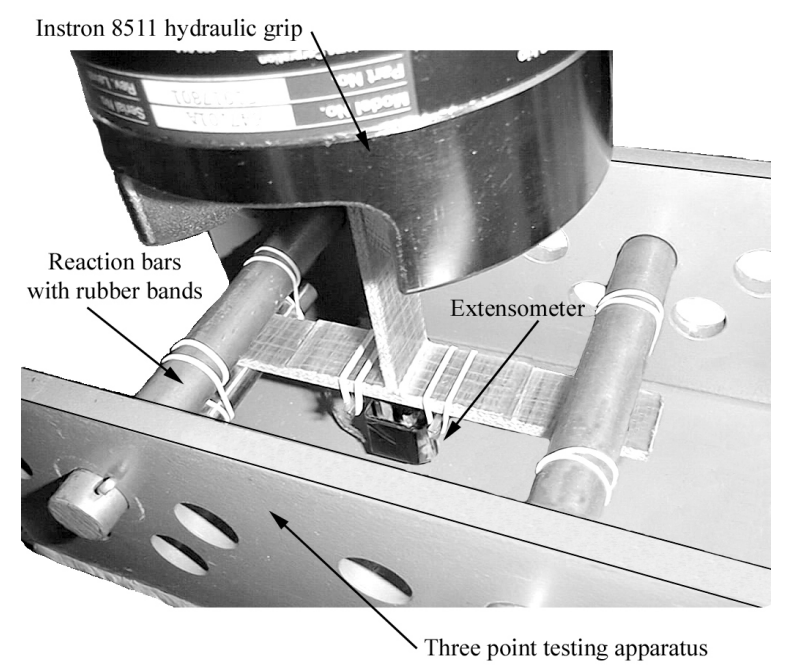

Figure 11. Typical Skin-Stiffener Fatigue Test. 


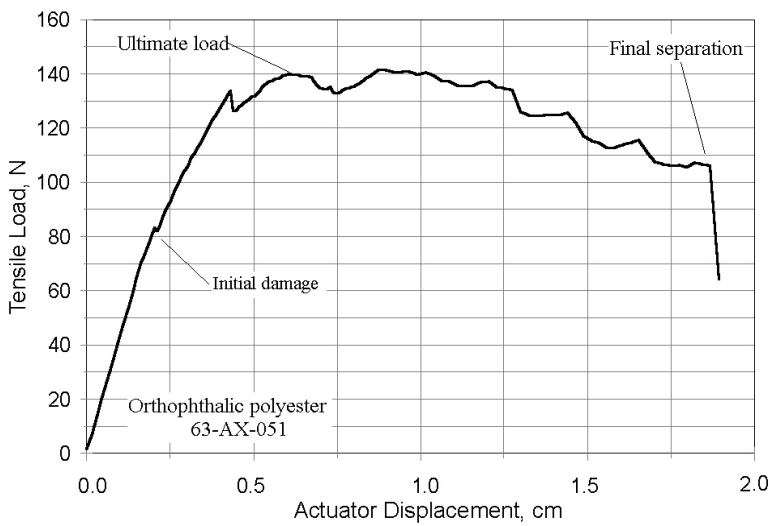

Figure 12. Typical Static Tensile Load versus Displacement Curve for a Skin-Stiffener Specimen.

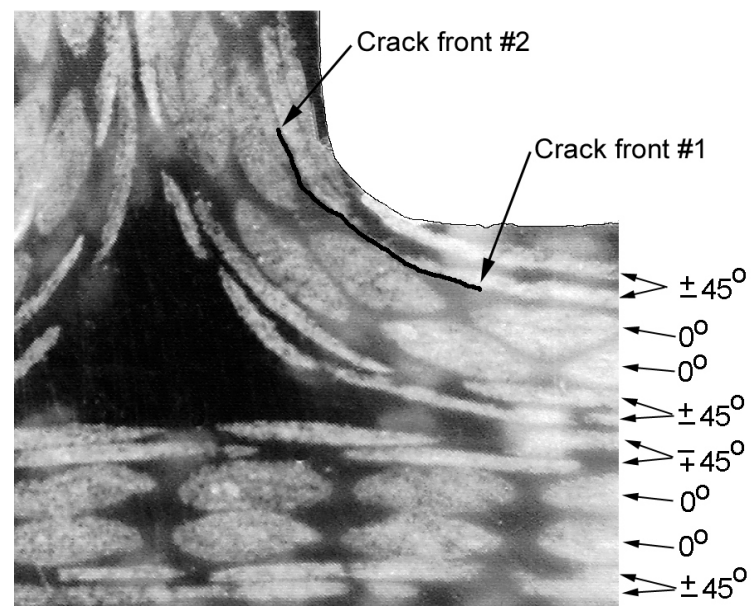

Figure 13. Location of Delamination and Nomenclature for Crack Fronts Under Static Loading (crack is in the $0^{\circ} / 45^{\circ}$ interface).

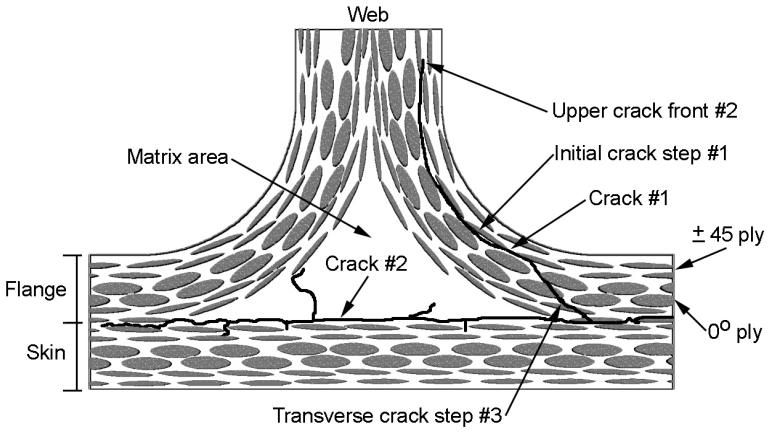

Figure 14. Skin-Stiffener Crack Sequence During Fatigue Loading. 


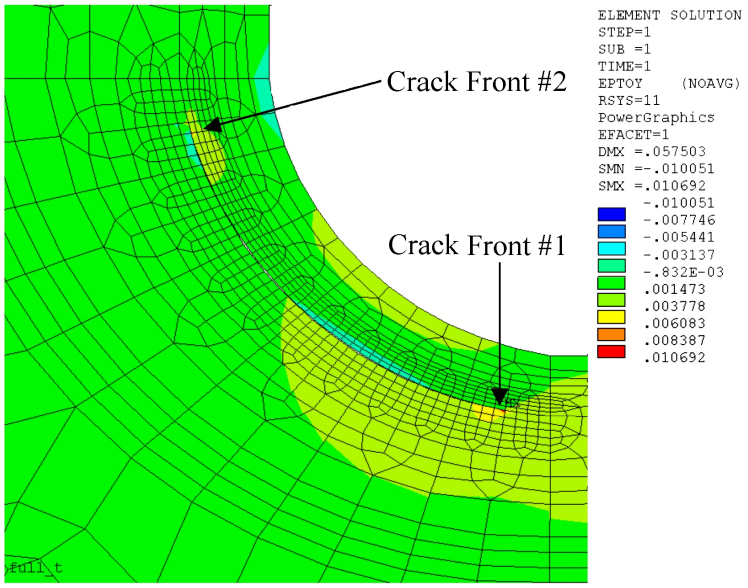

Figure 15. FEA Tangential Strain Plot with Crack Front Locations.

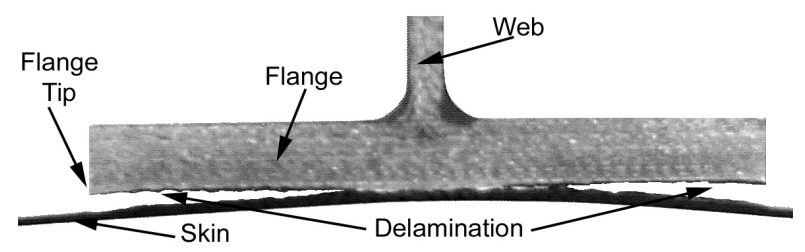

Figure 16. Photograph of Flange Tip Delamination for Thick-Flanged, Thin-Skin Stiffener Specimens.

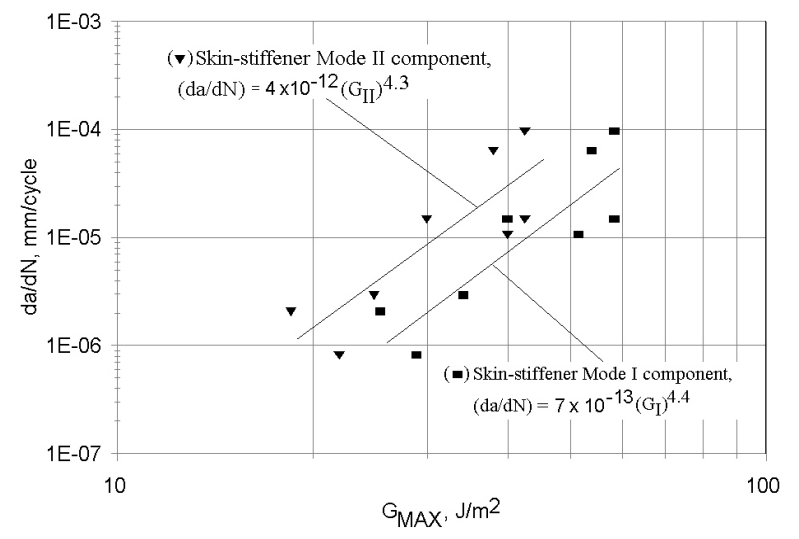

Figure 17. Fatigue Crack Growth Rate versus $\mathrm{G}_{\max }$ in the $0^{\circ} / 45^{\circ}$ Interface of Ortho-Polyester Skin-Stiffeners. 


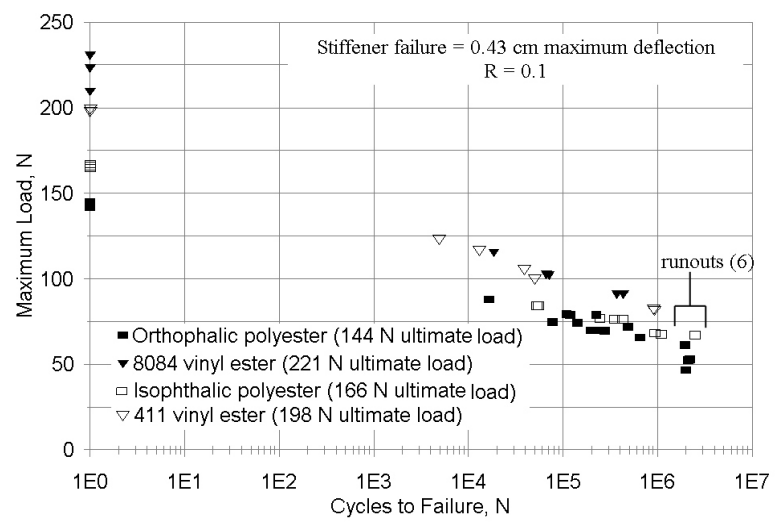

Figure 18. Comparison of Different Matrix Materials in Fatigue Life S-N Data for Skin-Stiffeners. (Maximum Cyclic Load versus Number of Cycles to Reach a Deflection of $0.43 \mathrm{~cm}$ ). 